\title{
CRIAÇÃO DE CONHECIMENTO NO AGRONEGÓCIO: ESTUDO DE CASOS
}

\author{
Knowledge Creation in Agribusiness: cases study
}

\section{Erlaine Binotto ${ }^{1}$ \\ Elisabete Stradiotto Siqueira ${ }^{2}$ Marina Keiko Nakayama ${ }^{3}$}

\section{Resumo}

Este artigo objetiva demonstrar, com base no modelo de Nonaka e Takeuchi (1997), os aspectos presentes na criação de conhecimento em propriedades rurais no Brasil e na Austrália. Caracteriza-se por um estudo descritivo de dois casos, utilizando-se de questionário, entrevista e focus group. Os resultados demonstraram haver significativas similaridades e diferenças entre as realidades, sendo que, no Brasil, os produtores rurais estão inseridos num contexto cooperativo e, na Austrália, os negócios são conduzidos individualmente. Para a ocorrência da criação de conhecimento, é necessária a existência de grupos de relacionamento e de certa liderança em nível de propriedade, de comunidades de prática (CoPs) ou da cooperativa. As CoPs não se constituem num processo tecnológico, e sim num processo social e cognitivo. Sua formação não depende somente de tecnologia, mas do estabelecimento de relações informais, nas quais as pessoas podem utilizar esses ambientes para realizar trocas, definir suas verdades quanto às suas posturas frente às mudanças.

Palavras-chave: Criação de Conhecimento; Comunidade de Prática; Propriedade Rural.

\footnotetext{
${ }^{1}$ Administradora, mestre e doutora em Agronegócios. Professora Adjunta na Universidade Federal da Grande Dourados - UFGD. E-mail: e-binotto@uol.com.br

${ }^{2}$ Graduada e mestre em Administração e doutora em Ciências Sociais. Professora adjunta da Universidade Federal do Semi-Árido - UFERSA. E-mail: betebop@uol.com.br

${ }_{3}^{3}$ Psicóloga, mestre e doutora em Administração. Professora do PPGC/UFSC. E-mail: marina.keiko.nakayama@gmail. com
} 


\begin{abstract}
This paper aims to show the present aspects on knowledge creation in rural properties in Brazil and in Australia. It is based on the Nonaka and Takeuchi (1997) model. It is a descriptive study of two cases using questionnaire, interview and focus group instruments. The results have demonstrated that there are some differences and similarities between farmers in a cooperative context in Brazil and farmers individually conducting business in Australia. In order to occur knowledge creation, group relationships and leadership in property, communities of practice (CoPs) and cooperatives are necessary. The CoPs are not an organized technological process, but a social and cognitive process and, like this, its formation does not seem to be dependent only on technology, but also on the establishment of informal relations, in which the individuals use those environments define their values and attitudes face to changes.
\end{abstract}

Keywords: Knowledge Creation; Community of Practice; Rural Property.

\title{
1 Introdução
}

O desenvolvimento do agronegócio brasileiro é resultado das mudanças no panorama econômico mundial, as quais provocam transformações nos agronegócios local, regional, nacional e internacional. Nesse contexto mutável, destaca-se a importância do capital humano como meio de se buscar novas oportunidades de negócios e do gerenciamento das mudanças (BATALHA, 2000). O conhecimento, muito mais que o trabalho intensivo, foi se tornando a maior riqueza. Para Jank (1997), as fortes mudanças estruturais que estão acontecendo no agronegócio nesta década são fatores que determinam a necessidade de novas relações, posturas e formas de conduta dos negócios para os envolvidos nesse setor.

$\mathrm{Na}$ atualidade, os produtores rurais são vistos como gerenciadores dos negócios muito mais do que supridores da produção primária, atuando em um mercado pouco conhecido ou sendo apenas executores de atividades técnicas. Deles são requeridas posturas gerenciais qualificadas, com conhecimentos atualizados, habilidades e competências, com vistas a atender a determinados mercados com crescentes exigências referentes a padrões, à qualidade e a inovações nos produtos. Vanclay (1992) complementa essa ideia afirmando que ser produtor rural é mais do que uma atividade operacional: é uma vocação e uma prática sociocultural.

Assim, um dos grandes desafios que se apresentam é como lidar eficazmente com as informações e tomar decisões nesse ambiente de incertezas. Para isso, é necessário não apenas processar informações, mas criar conhecimentos (NONAKA, 1994).

Sonka et al. (1999) trazem a noção de criação de conhecimento no agronegócio usando o modelo de Nonaka e Takeuchi (1997), com ênfase na agricultura de precisão e na tecnologia da informação, e mostram que ocorreram significativos avanços na disponibilidade e na capacidade de utilização da informação tecnológica nesse contexto, o que causa muitos impactos na sociedade. Os autores referem-se à criação de conhecimento, porém não evidenciam o modelo como um todo, detendo-se em alguns aspectos da teoria e relacionandoos restritamente à agricultura de precisão e à tecnologia da informação.

Muito se tem falado em criação de conhecimento, mas pouco se tem estudado sobre como esse processo se dá na prática, pois é evidente que os produtores rurais necessitam de tecnologias e informações para viabilizar seus processos, mas sem a base de conhecimentos pode ser tornar inviável operacional e economicamente. Por isso, é importante também o entendimento de como o conhecimento é criado nas rotinas diárias, pois, num mundo caracterizado por 
rápidas mudanças e transformações, a habilidade das organizações agronegociais de decifrar o ambiente, de buscar contribuições nele e de responder-lhe rapidamente tem despertado interesse tanto teórico quanto prático.

Este artigo objetiva demonstrar os aspectos presentes na criação de conhecimento em propriedades rurais no Brasil e na Austrália com base no modelo de Nonaka e Takeuchi (1997). O estudo desenvolveu-se em uma realidade no estado do Rio Grande do Sul, Brasil, e em outra no estado de Queensland, na Austrália. A delimitação do estudo aos dois estados deveu-se aos limites de tempo e de recursos para o desenvolvimento da pesquisa e também por se considerar que cada estado do Brasil, bem como da Austrália, possui suas particularidades no que se refere à produção, ao clima e a outros aspectos, o que poderia dificultar as análises das situações diferenciadas no estudo. Salienta-se também que, no decorrer do artigo, quando a referência for ao Brasil e à Austrália, será feita especificamente a esses estados.

\section{Revisão teórica}

\subsection{Gestão do conhecimento e a criação de conhecimento}

O termo gestão do conhecimento já era mencionado em décadas anteriores (GOERL, 1975; HENRY, 1975; MCCAFFERY, 1975), bem como o de capital intelectual (FEIWEL, 1975). Na década de 1990, Stewart (1998) popularizou o conceito de capital intelectual e trouxe a ideia de bem intangível. Após o conceito ser definido, tem crescido o número de publicações dando ênfase à gestão do conhecimento e capital intelectual, com a tendência a se chegar, até 2010, a dez mil publicações (SERENKO e BONTIS, 2004). Mcadam e Mccreedy (1999) salientam que as publicações abrangem muitas disciplinas e áreas de interesse tanto de acadêmicos como de outros pesquisadores, entretanto gestão do conhecimento não é uma simples questão de capturar, estocar e transferir informação; requer interpretação e organização da informação em múltiplas perspectivas (BHATT, 2001).

Para melhor compreensão do que seja conhecimento, torna-se necessário diferenciálo de informação e de dado. Embora haja certa complexidade na definição de dado, informação e conhecimento, é possível fazer uma distinção mais clara (BHATT, 2001). Para Nonaka e Takeuchi (1997), há uma nítida distinção entre os conceitos.

Buscando demonstrar o significado de dado, informação e conhecimento, na Figura 1 reúnem-se as ideias de alguns autores, como Bhatt (2001), Nonaka e Takeuchi (1997), Huber (1991), Davenport e Prusak (1998), Hedlund e Nonaka (1993), Leonard e Sensiper (1998) e Brown e Duguid (2001).

A complexidade no entendimento do que seja dado, informação e conhecimento, pode ser justificada por envolver certo grau de subjetividade, visto que somente os seres humanos são capazes de transformar dado e informação em conhecimento. Para Nonaka e Takeuchi (1997) e Nonaka, Toyama e Byosiere (2001), a informação objetiva oferece um novo ponto de vista para a interpretação de eventos e objetos, possibilitando que sejam vistos significados que antes eram invisíveis. 


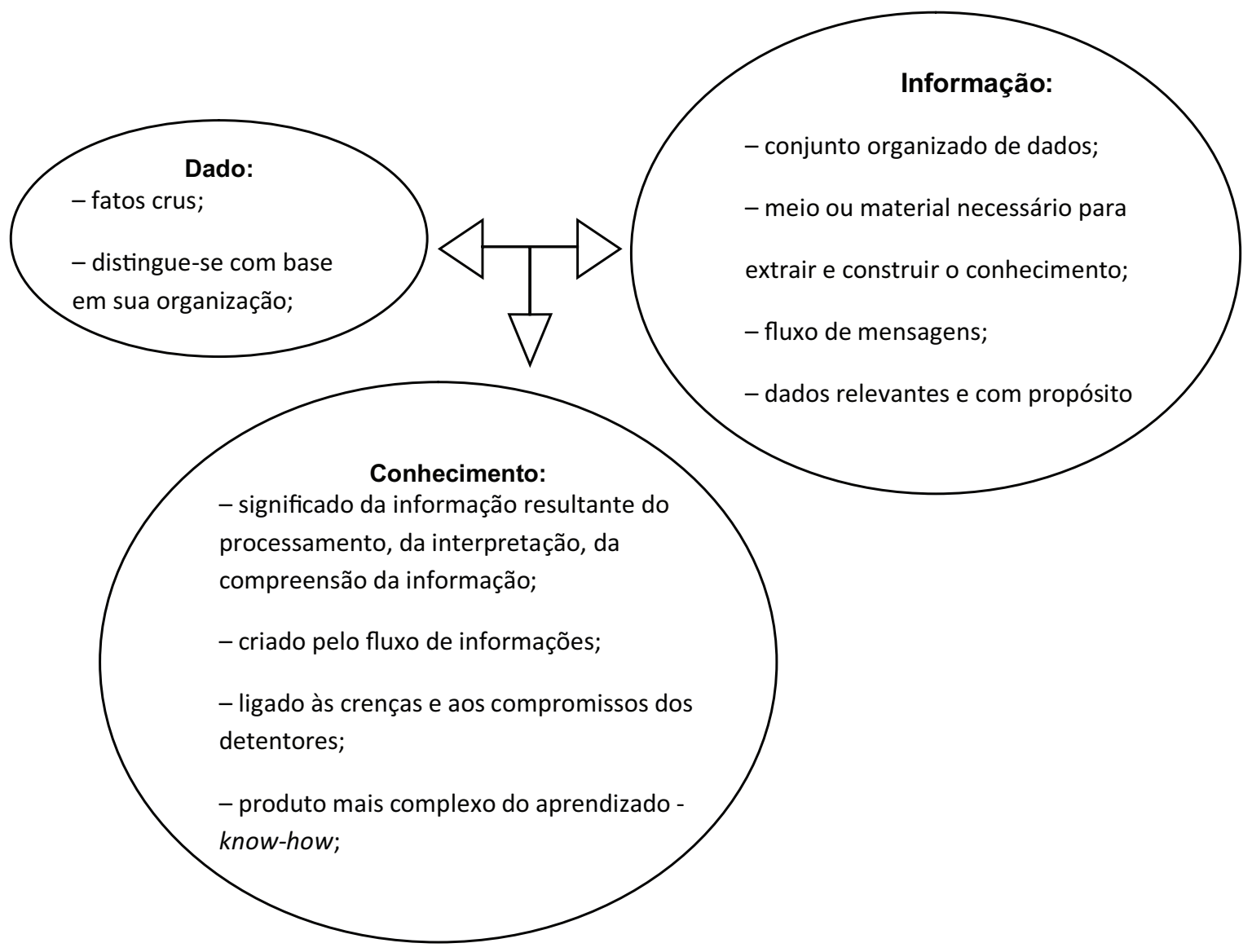

Fonte: Elaborada pelas autoras

Figura 1 - Dado, informação e conhecimento.

Nonaka (1991, 1994), Nonaka e Takeuchi (1997), Spender (1996, 1998) e Blackler (1995) têm desenvolvido estudos que auxiliam no entendimento da criação de conhecimento e das formas como tem sido utilizado nas organizações ou das mudanças no domínio das formas de conhecimento organizacional num nível amplo na organização.

Os conhecimentos tácito e explícito são os que melhor representam o conhecimento no contexto organizacional na perspectiva de Nonaka e Takeuchi (1997). A distinção entre ambos não implica uma separação das duas partes do todo; ao contrário, seu caráter indivisível e de interdependência envolve trocas permanentes, interações constantes, gerando formas particulares de conversão do conhecimento (NONAKA, UMEMOTO e SENOO, 1996; NONAKA e TAKEUCHI, 1997). Para Nonaka, Toyama e Byosiere (2001), apesar de toda a atenção dada à questão da criação de conhecimento organizacional, é pouco conhecido o modo como as organizações criam e gerenciam conhecimento. Por isso, esse estudo dá ênfase à criação de conhecimento.

Para definir conhecimento tácito, Polanyi (1967) toma como frase-chave "we can know more than we can tell" (nós conhecemos mais do que somos capazes de expressar), ou seja, a habilidade das pessoas de conhecerem além daquilo que é expresso pela fala por saberem mais do que podem verbalizar, ou seja, o conhecimento vai além das possibilidades da língua. Nenhuma quantidade de conhecimento explícito proporciona a parte tácita; são duas dimensões do conhecimento distintas, de modo que a tentativa de reduzi-las compara-se à tentativa de transformar um desenho de duas dimensões em uma única (POLANYI, 1967). 
Polanyi (1967) apresenta uma significativa rejeição à análise restrita ao conhecimento absolutamente objetivo, dando bastante relevância ao conhecimento tácito em todos os casos. Para o autor, a busca de explicitação de todo conhecimento, eliminando o elemento tácito pessoal, pode destruí-lo. O tácito inclui a habilidade de perceber particularidades que constituem os indivíduos, grupos e organizações.

A abordagem ligada à criação de conhecimento adota, predominantemente, uma perspectiva organizacional para a análise e considera que o novo conhecimento é criado através da dinâmica interação entre indivíduos com diferentes tipos de conhecimentos tácitos e explícitos e com diferentes conteúdos (NONAKA, 1991, 1994; NONAKA, UMEMOTO e SENOO, 1996; NONAKA e TAKEUCHI, 1997).

Assim, o modelo apresentado por Nonaka e outros autores em diferentes estudos (NONAKA, 1991, 1994; NONAKA, UMEMOTO e SENOO, 1996; NONAKA e TAKEUCHI, 1997; NONAKA e KONNO, 1998; NONAKA, REINMOELLER e SENOO, 1998; NONAKA e REINMOELLER, 2000; NONAKA, TOYAMA e KONNO, 2000; NONAKA, REINMOLLER e TOYAMA, 2001; NONAKA, TOYAMA e BYOSIERE, 2001) pode ser considerado um dos que melhor conseguiu desenvolver uma abordagem que traz o processo social e epistêmico em um modelo coerente, relacionando a inovação aos conhecimentos tácitos e explícitos da organização. O modelo mostra como as empresas japonesas geram a dinâmica da inovação. Esses autores veem a criação de conhecimento como um processo interativo entre o racional e o empírico, mente e corpo, análise e experiência e entre implícito e explícito.

"Empresas criadoras de conhecimento" são aquelas que criam conhecimento de forma sistemática, que os disseminam por toda a organização e que possuem a capacidade de incorporálos em novos produtos e tecnologias. São lugares onde a geração de novos conhecimentos acontece não como atividade especializada, mas como uma forma de comportamento, um meio pelo qual todos são trabalhadores do conhecimento (NONAKA e TAKEUCHI, 1997). Para Marakas (1999, p. 440), "a criação de conhecimento refere-se à habilidade de uma organização de desenvolver conhecimento novo e usar as ideias e soluções".

Por sua vez, Nonaka (1991, 1994), Nonaka e Takeuchi (1997), Nonaka, Toyama e Byosiere (2001) e Nonaka, Umemoto e Senoo (1998), em seus modelos, apresentam os quatro modos de conversão: de tácito em tácito, chamado pelos autores de socialização; de tácito em explícito, externalização; de explícito em explícito, combinação; e de explícito em tácito, internalização.

O centro da teoria de Nonaka e Takeuchi (1997, p. 62) consiste na espiral da criação de conhecimento: "[...] a espiral surge quando a interação entre conhecimento tácito e conhecimento explícito eleva-se dinamicamente de um nível ontológico inferior até níveis mais altos". Os autores salientam que o segredo para a criação de conhecimento está na mobilização e na conversão do conhecimento tácito. Desse modo, relatam a existência de duas dimensões do conhecimento: a epistemológica e a ontológica.

A dimensão epistemológica está baseada na distinção entre conhecimento tácito e explícito, ao passo que a ontológica abrange os níveis de entidades criadoras do conhecimento: individual, coletivo, organizacional e interorganizacional. Desse modo, quando há uma interação entre o conhecimento tácito e o explícito, o nível ontológico eleva-se até os níveis mais elevados, surgindo a espiral de criação de conhecimento, a qual permite a propagação do conhecimento individual até que faça parte de uma rede de conhecimentos entre organizações.

Nonaka (1994) apresenta o aprendizado como resultado da participação em uma comunidade de interação, envolvendo mais a aquisição de uma nova identidade do que o conteúdo cognitivo. Nas Comunidades de Prática (CoPs), está presente um aspecto importante 
do conhecimento e, especificamente, a parte tácita e não formalizada, que pode ser perpetuada e modificada, aumentando o aprendizado (GHERARDI e NICOLINI, 2000). Seu conceito e suas características são apresentados a seguir.

\subsection{Comunidades de prática}

O termo CoP foi apresentado, primeiramente, por Lave e Wenger (1991) em seu livro Situated Learning. Os autores mostram como ocorre o aprendizado e a comunicação simultânea em termos da prática e da comunidade. O aprendizado de uma prática envolve tornar-se membro de uma CoP, não implicando simplesmente uma questão de adquirir informações; mas sim, disposição, conduta e perspectiva profissional. Na CoP está presente um aspecto importante do conhecimento e, especificamente, a parte tácita e não formalizada, que pode ser perpetuada e modificada, aumentando o aprendizado (GHERARDI e NICOLINI, 2000).

Na concepção de Wenger e Snyder (2001), a CoP é um grupo de pessoas informalmente ligadas pelo conhecimento especializado compartilhado e pela paixão por um empreendimento conjunto. O foco é o que as pessoas aprendem e como aprendem no contexto social através da participação no mundo social. Lave e Wenger (1991) descrevem as CoPs como um processo com limites que são históricos, com relações de longo prazo entre as pessoas e seus espaços. Para eles, o desenvolvimento do aprendizado concerne ao desenvolvimento do conhecimento identificado na prática. A CoP é a condição intrínseca para a existência do conhecimento e para que possam ser adotadas as melhores práticas e obtido um padrão na atividade (LAVE e WENGER, 1991; WENGER, 2000).

Com o advento da era da informação, muitas das CoPs podem se utilizar de outras formas para realizar os contatos. Com isso, surge o termo comunidades de prática virtuais, que se valem dos recursos disponíveis da tecnologia da informação, seja através de e-mail, chat, telefone, dentre outros.

Nas comunidades de praticantes, é rejeitada a ideia da simples transferência de conhecimento pelo fato de isolar o conhecimento da prática; considera-se o conhecimento como algo teórico, e aborda-se a questão da aprendizagem como algo socialmente construído, conectando o que está sendo aprendido com as condições nas quais isso ocorre (BROWN; DUGUID, 1991; DUGUID e BROWN, 2001).

O grau de dependência dos grupos varia de acordo com a forma como eles funcionam juntos. Os membros são informalmente limitados pelos valores que encontram no aprendizado, no trabalho conjunto, no engajamento, na discussão e na solução de problemas (WENGER, 2000). Lave (1991) e Wenger (1998) consideram que esse mundo, por si só, é socialmente construído, visto que o homem é um ser social que constrói sua identidade nas relações. O aspecto humano de uma CoP é o mais importante (KIMBLE, HILDRETH e WRIGHT, 2001).

Wenger e Snyder (2001), Wenger, Mcdermott e Snyder (2002) e Murty (2004) apresentam algumas características das CoPs e comparam-nas a outras formas de organização. 


\begin{tabular}{|c|c|c|c|}
\hline Características & CoPs & Time de Projeto & Rede Informal \\
\hline Objetivo & $\begin{array}{l}\text { Desenvolver nos participantes } \\
\text { aprendizado, criação de } \\
\text { conhecimento e competências }\end{array}$ & Realizar determinada tarefa & $\begin{array}{l}\text { Colher e transmitir informações } \\
\text { empresariais }\end{array}$ \\
\hline Participantes & \begin{tabular}{|l|} 
Participantes que se auto-selecionam \\
\end{tabular} & $\begin{array}{l}\text { Empregados escolhidos por } \\
\text { gerentes seniores }\end{array}$ & $\begin{array}{l}\text { Amigos e conhecidos do meio } \\
\text { empresarial }\end{array}$ \\
\hline $\begin{array}{l}\text { O que possuem } \\
\text { em comum }\end{array}$ & $\begin{array}{l}\text { Paixão, compromisso e identificação } \\
\text { com habilidades comuns do grupo }\end{array}$ & $\begin{array}{l}\text { As metas e pontos importantes } \\
\text { do projeto ou objetivos }\end{array}$ & $\begin{array}{l}\text { Necessidades mútuas e } \\
\text { conhecimento interpessoal }\end{array}$ \\
\hline Duração & $\begin{array}{l}\text { Sem tempo prédeterminado para } \\
\text { acabar ou enquanto houver interesse } \\
\text { em manter o grupo }\end{array}$ & $\begin{array}{l}\text { Temporário, termina quando o } \\
\text { projeto entregue é concluído }\end{array}$ & $\begin{array}{l}\text { Enquanto as pessoas tiverem um } \\
\text { motivo para manterem contato }\end{array}$ \\
\hline Limite & Domínio do conhecimento & Registro formal & Relações mais amplas \\
\hline Conexão & Aplicação de uma prática & Compromisso com os objetivos & \\
\hline $\begin{array}{l}\text { Permanência do } \\
\text { Grupo }\end{array}$ & Membros constantes & $\begin{array}{l}\text { Membros constantes durante o } \\
\text { projeto }\end{array}$ & $\begin{array}{l}\text { Ligações baseadas nos } \\
\text { conhecimentos }\end{array}$ \\
\hline
\end{tabular}

Fonte: Adaptado de Wenger e Snyder (2001); Wenger, Mcdermott e Snyder (2002) e Murty (2004)

Quadro 1 - Comparação de CoP com outras formas de organização.

A CoP inclui os aspectos formal e informal da organização, sendo mais duradouros que o time e mais estruturados que as redes informais. O grupo identifica-se como CoP pelo fato de ter interesses comuns em algo que é comum a todos; centra-se na motivação, é autogerenciável, auto-selecionável e possui uma série de interesses motivados pelo modelo de trabalho (BROWN e DUGUID, 2001). O que impulsiona a perpetuação das CoPs é a geração de conhecimento, provocando o seu reforço e renovação (WENGER e SNYDER, 2001).

A confiança é construída através da interação no decorrer do tempo, na medida em que as pessoas podem fazer questões ou expor as suas dúvidas sem medo de mostrar sua ignorância sobre um assunto. É possível, entre os membros do grupo, identificarem e conhecerem quem pode dar uma resposta para uma dúvida surgida; sentirem-se mais confidentes e serem bemvindos ou reconhecerem que alguém é suficientemente competente em determinado aspecto para que o tempo seja gasto numa discussão (WENGER, 2000).

Enfim, a CoP pode ajudar na criação de uma infraestrutura social que poderia capacitar a criação e a transferência do conhecimento. Pelo fato de seu foco estar na aprendizagem, no desenvolvimento de capacidades e na difusão do aprendizado entre os membros do grupo, aumentam as capacidades para a solução de problemas e a realização de melhoramentos em todos os aspectos.

Assim, de acordo com alguns autores (BROWN e DUGUID, 1991; LAVE, 1991; LAVE e WENGER, 1991; WENGER, 1996, 1998; WENGER, 2000; WENGER e SNYDER, 2000; WENGER e SNYDER, 2001; WENGER, MCDERMOTT e SNYDER, 2002), a CoP caracteriza-se por:

- $\quad$ aprender com a participação social;

- $\quad$ compartilhar práticas, valores, insights, objetivos e interesses;

- $\quad$ compartilhar especificidades da área de atuação e solução de problemas;

- aumentar a motivação no trabalho, reputação profissional e produtividade;

- ter um conjunto comum de focos em problemas e senso de propósito;

- $\quad$ engajar as pessoas em um processo de encorajamento para o compartilhamento,

criação e uso do conhecimento; 
- $\quad$ criar um respeito mútuo e confiança para a realização de trocas;

- encorajar as pessoas a realizar trocas, expor as "ignorâncias", fazer questões difíceis e ouvir cuidadosamente;

- ter conhecimento coletivo e necessidades reais para conhecer o que cada um conhece;

- $\quad$ ser auto-organizada;

- criar uma "fábrica" de aprendizado;

- $\quad$ ser formal ou informalmente organizada.

Na comunidade virtual, as características são as mesmas: as pessoas mantêm contatos informais para trocar ideias sobre temas que possuem interesse comum, e o que as diferencia são os contatos à distância. Isso não significa que não possam existir contatos presenciais, que podem ser esporádicos e não-programados.

O que se mostra importante ao se falar de CoPs é o aspecto cultural. A visão de cultura sugere que, assim como ocorre com as pessoas, as organizações têm a capacidade de resistir à mudança ou de incorporá-la; porém, mesmo que a organização de aprendizagem seja possível, isso poderá ser uma limitação (PEDLER, 1992).

A cultura é um traço que identifica e diferencia as organizações em suas particularidades. Alguns aspectos não são possíveis de explicitação, por serem cercados de subjetividade que nem sempre é interessante explicitar; já outros aspectos são pontualmente gerenciáveis e podem ser explicitados. Algumas culturas podem inibir a capacidade de aprendizagem das pessoas, visto que a verdadeira aprendizagem não ocorre somente quando a organização refina as suas teorias e pressupostos acerca da forma como o mundo funciona, mas constitui-se num processo contínuo. A extensão em que cada indivíduo interage com o outro depende da cultura organizacional (BHATT, 1998). Enfim, a cultura inclui todas as áreas da vida do grupo (SCHEIN, 1990).

Para Schein (1985), cultura resulta do compartilhamento de experiências importantes no processo de solução de problemas internos e externos, o qual pode levar a uma visão de mundo construída pelo grupo. Assim, cultura é fruto do aprendizado da experiência do grupo e pode ser encontrada somente onde há um grupo definido com uma história significativa. Cultura é conceituada como a construção coletiva da realidade social (SACKMANN, 1991). As histórias, os modelos mentais, que não somente servem de orientação, mas também de obstáculo para que o aprendizado ocorra (HEDBERG, 1981), estão inseridos no aspecto cultural. Esse conceito é o que melhor se ajustar a este estudo.

\section{Metodologia}

A pesquisa caracteriza-se por um estudo descritivo de caráter qualitativo, complementado por dados quantitativos. Delineia-se por estudo de casos, utilizando-se de documentação e observação in loco, questionário, entrevista e focus group. Foi desenvolvida com produtores rurais de uma região do Rio Grande do Sul, no Brasil, e de Queensland, na Austrália.

No Brasil, fizeram parte da amostra produtores associados da Cooperativa Tritícola Mista Alto Jacuí Ltda. (Cotrijal), situada na região nordeste do estado do Rio Grande do Sul, cujas atividades são ligadas à produção de grãos. Participaram também os gerentes e alguns funcionários da cooperativa. Na Austrália, foram produtores que atuam em diferentes atividades numa realidade sem cooperativas agrícolas. Também participaram pesquisadores da universidade e funcionários do Department Prime Industry and Fisheries (DPI\&F1). Além disso, 
foram realizadas observação e análise documental nas duas realidades. Com isso, acreditase ter realizado triangulação dos dados resultantes dos diferentes instrumentos. O estudo desenvolveu-se entre 2001 e 2004.

Para a análise dos dados qualitativos, foi utilizada análise de conteúdo de acordo com a metodologia de Krippendorff (2004) e, para os dados quantitativos, foi usada análise estatística.

\section{Resultados da Pesquisa}

No Brasil, a cooperativa é um elo da cadeia produtiva e exerce um papel intermediário entre o produtor e a indústria, embora, muitas vezes, industrialize alguns produtos; dá, ainda, suporte ao produtor para se adequar às exigências de produtos e mercados. Na Austrália, os produtores estão ligados diretamente às indústrias, que, em muitos casos, absorvem toda a sua produção por meio de contratos; cabe-lhes, assim, a busca por esses espaços nas indústrias e a adequação em termos de especificações dos produtos como elo de uma cadeia produtiva.

O modelo de Nonaka e Takeuchi (1997), com base nas realidades estudadas, deu suporte à construção de uma figura representativa (Figura 2) para demonstrar como se dá a criação de conhecimento nas mesmas.

Em ambas as realidades, o mercado externo, a situação econômica do país e a política agrícola do governo exercem forte influência sobre o agronegócio, contudo a intensidade do impacto dessas variáveis sobre os elos das cadeias produtivas varia de acordo com o contexto em que os negócios estão inseridos. Essas variáveis podem tanto oferecer maiores vantagens como até mesmo inviabilizar o desenvolvimento das atividades agrícolas.

A realidade brasileira estudada caracteriza-se por uma sociedade permeada por aspectos culturais originados de europeus, principalmente italianos, alemães e holandeses, que chegaram à região nordeste do RS há muitos anos. Apresenta as organizações cooperativas como suporte aos produtores rurais, que, diante das dificuldades para a realização de suas atividades, buscaram novas formas de organização. Eles sentiram necessidade do apoio de algum grupo ou instituição, uma vez que o governo não lhes oferecia o suporte necessário. Atualmente a cooperativa assessora-os por meio de cursos, dias de campo, palestras, da Expodireto, onde são expostas novas tecnologias e variedades de sementes, dentre outras formas de qualificação. As CoPs formam-se com base nesse ambiente de interação, onde o compartilhamento de informações e conhecimentos pode acontecer. 


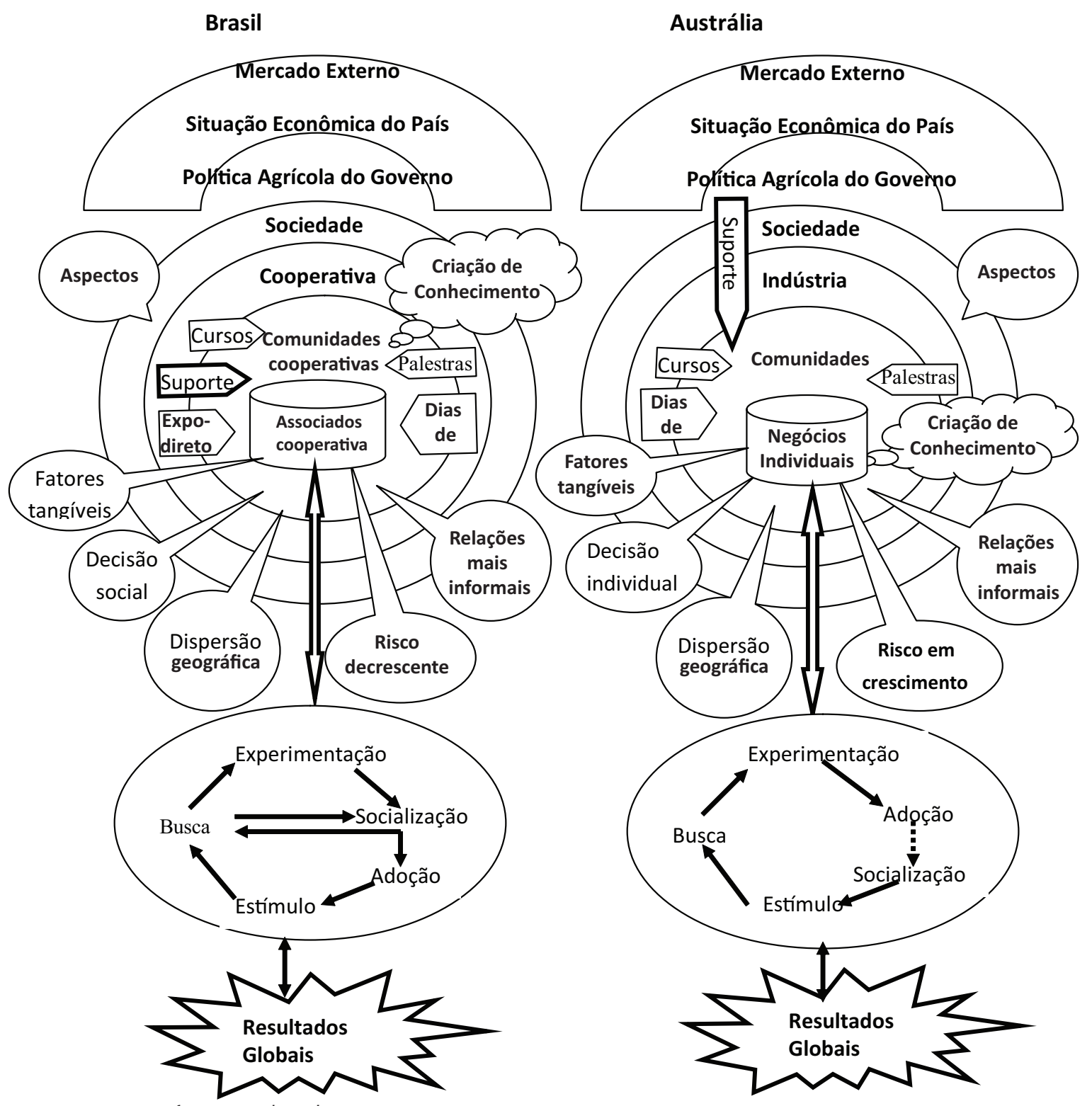

Fonte: figura criada pelas autoras

Figura 2 - Fatores que envolvem o processo de criação de conhecimento no elo da produção nos agronegócios brasileiro e australiano

As decisões tomadas nessas CoPs consideram a existência de um grupo que atua em uma base cooperativa e voltam-se ao desenvolvimento e ao crescimento do corpo social. Para dar maior suporte à formação de grupos e CoPs, a cooperativa desenvolve trabalhos com foco na liderança, como eleger líderes nas comunidades, para que sejam disseminadores de informações da organização e estimuladores de constante qualificação e inovação nas CoPs. Pode-se inferir, portanto, que o estímulo ao desenvolvimento das lideranças exerce forte influência no ambiente da propriedade, que conta com a participação ativa da mulher. Nesse sentido, os produtores pesquisados afirmaram que a atuação das mulheres vem crescendo tanto na administração da propriedade como na atuação junto à cooperativa como líder de comunidade, o que foi possível observar pela participação ativa de muitas delas na pesquisa, respondendo a questionários, a entrevistas e no focus group. 
As relações entre os associados da cooperativa e, de certa forma, entre os dirigentes caracterizam-se pela informalidade. Os associados utilizam diferentes oportunidades para realizar trocas de informações entre si, entre as quais estão, além das atividades desenvolvidas pela cooperativa e das visitas semanais à organização, que auxiliam na criação de vínculos, os encontros na igreja, no clube social, nos jogos de futebol e festas, as rodadas de chimarrão nos grupos sociais e os encontros em reuniões em escolas onde os filhos estudam. Esse estilo de relações está diretamente ligado aos aspectos culturais próprios da sociedade. As facilidades nos encontros face a face devem-se também à pequena dispersão geográfica entre os produtores nessa realidade.

Com o suporte da cooperativa, há tendência de redução nos riscos no gerenciamento da atividade dos associados; por outro lado, com a organização oferecendo serviços e suporte financeiro, seus riscos crescem. A partir do momento em que o governo passou a não assumir totalmente a função de suporte aos produtores rurais, a cooperativa exerce esse papel, a fim de viabilizar o desenvolvimento de seu associado. Com essa postura, mostra-se cumprindo seu papel de garantir ao produtor rural a renda, o nível de exploração rural e de organização da produção agroindustrial, bem como a regularização do mercado.

Os fatores tangíveis se mostraram exercer influência na criação de conhecimento por poderem ser limitadores das trocas, até mesmo, do estímulo à busca de algo novo. Alguns pesquisados comentaram que "não se sentiam grandes o suficiente para inovar" e que "não dá para inovar sem recursos financeiros". Para alguns produtores, os valores tangíveis, tais como tamanho da propriedade, equipamentos, condições financeiras, dentre outros fatores, são determinantes para terem ou não maiores perspectivas futuras quanto à atividade, bem como estímulos para a busca de algo novo.

A criação de conhecimento ocorre no ambiente cooperativo, no qual a cooperativa, em diferentes momentos de interação, estimula os associados a inovar, ou seja, busca criar um campo para a interação dos associados. Acredita-se que o processo individual de criação de conhecimento do associado da cooperativa passa por diferentes estágios e não possui um ponto de referência inicial. As diferentes formas de interação oferecidas pela cooperativa podem instigar o associado a buscar algo novo; ao receber o estímulo, ele vai à busca de mais informações através do contato com os técnicos da organização, com outros associados ou junto a outras fontes. Após essas fases, ele socializa ou experimenta a novidade em sua propriedade e, posteriormente, socializa-a com a CoP ou as CoPs de associados de que faz parte. Após o compartilhamento com outros produtores, o associado pode buscar mais informações, ser estimulado para novas buscas ou colocá-las em ação como uma prática cotidiana na sua propriedade.

Portanto, a cooperativa demonstrou ser a base para o estímulo à criação de conhecimento através das CoPs que vão se formando no decorrer das situações de interação, as quais demonstraram necessitar de tempo para sua maturação e gerar resultados. Assim, inferese que o processo de criação de conhecimento está institucionalizado na cooperativa através das muitas formas de interação com os associados e dos vínculos existentes entre ambos. Diante disso, as CoPs, no ambiente cooperativo, podem agregar valor aos processos, aos produtos e aos serviços através do espaço e das possibilidades para o desenvolvimento profissional e para o compartilhamento de ideias e ideais.

Como decorrência de todo o processo de criação de conhecimento envolvendo essas variáveis, há um objetivo maior, que é a obtenção de resultados globais, os quais se referem a aspectos tangíveis e intangíveis. Esses podem ser motivadores para que haja estímulo à busca de aperfeiçoamento nas atividades que lhes garantam sobrevivência e bons resultados em um 
mercado competitivo.

No que se refere à realidade australiana, constatou-se que a sociedade caracterizase por aspectos culturais oriundos, principalmente, dos colonizadores ingleses, embora nessa realidade também se encontrem pessoas vindas de outras regiões da Europa e da Ásia. Nesta região estudada, não foram identificadas cooperativas agrícolas. Os produtores estão diretamente ligados às indústrias ou a outros tipos de empresas que compram a sua produção dentro das especificações e padrões requeridos pelo mercado. Essas empresas oferecem cursos, palestras e dias de campo com o objetivo de demonstrar seus produtos aos produtores e, ao mesmo tempo, para que sejam consumidos por eles. O DPI\&F também oferece algumas formas de qualificação, que, contudo, segundo os produtores, têm sido bastante limitadas. Para os profissionais desse departamento, os workshops têm sido a forma mais eficaz de qualificar os produtores, porém, na perspectiva dos produtores, não é a mais adequada, pois preferem a assistência personalizada e qualificada, como ocorria no passado.

Os fatores tangíveis exercem influência no processo de criação de conhecimento, conforme os produtores afirmaram, porque buscam algo novo quando percebem nisso um retorno financeiro: "Preciso ver o lucro no final". As condições financeiras exercem influência nessa decisão, na medida em que muitos produtores afirmaram se considerar pequenos para empreender e, assim, obter bons resultados.

Com esse cenário, as decisões são tomadas em nível individual ou da propriedade, uma vez que não se mostrou claramente a existência de uma organização formal que tenha o objetivo de dar suporte permanente aos associados; apenas alguns pesquisados demonstraram receber algum suporte limitado das instituições governamentais. Desse modo, os riscos ligados às atividades dos produtores tendem a crescer, uma vez que apenas eles suportam suas atividades desde a captação de recursos financeiros até inovações necessárias e busca de mercado para seus produtos. Portanto, a liderança para o desenvolvimento dos processos demonstrou ser exercida em nível de propriedade por um ou mais membros da família.

Nesse aspecto, é importante salientar o papel que as mulheres assumem no contexto, visto que os pesquisados manifestaram ter havido relevante crescimento na atuação feminina. Nos discursos durante a realização dos focus groups, ficou evidente que elas assumem uma parte da administração da propriedade, com função e papel definidos; têm participação muito semelhante à dos homens em questionamentos e discussões em reuniões com órgãos de pesquisa ou nas discussões do setor. Assim, os papéis que as mulheres exercem na administração da propriedade na Austrália denotaram estar mais definidos que nas propriedades no Brasil.

A criação de conhecimento ocorre no ambiente da propriedade rural, uma vez que os negócios são conduzidos de maneira individual, ou seja, em nível de propriedade. Os produtores rurais buscam informações e conhecimentos em ambientes diversos, mas é na propriedade que as decisões são tomadas e os rumos são definidos. Os discursos coletados permitem entender essa afirmação: “Vou lá, pego o que me interessa, volto para casa e vejo o que vamos fazer", revelando as oportunidades para obtenção de informações e conhecimentos e o ambiente onde as decisões são tomadas. Esse modo de proceder também se deve à grande dispersão geográfica entre os produtores da região estudada, cujas CoPs possuem, como meio de interação, telefone, e-mail e algum eventual encontro face a face.

No que se refere ao processo individual de criação de conhecimento do produtor, não há um ponto de referência para o início do processo. Deduz-se que, quando ele é instigado a buscar algo novo para sua atividade, sofre o estímulo vindo de diferentes fontes, tais como dias de campo, jornais, TV, internet, contato com outros produtores, com empresas do ramo, etc. Com esse estímulo vai à busca de mais informações nas diferentes fontes que costuma acessar, 
e, de posse dessas, inicia os experimentos em sua propriedade e adota a nova prática; então, só depois decide se as socializa ou não com a CoP ou as CoPs de que faz parte, quando poderá receber novo estímulo.

Os pesquisados demonstraram manter relações mais formais, o que pode estar ligado aos aspectos culturais característicos da sociedade. Eles realizam contatos com algumas pessoas que conhecem e que consideram que possam lhes permitir trocas "suficientemente inteligentes"; com esses costumam socializar conhecimentos ou buscar respostas aos seus questionamentos. Percebeu-se que os produtores buscam informações junto a outros produtores com quem compartilham algo que tenham descoberto. Dispersos geograficamente, eles demonstraram reservar as suas descobertas para suas próprias práticas para terem seus mercados garantidos.

A forma de os produtores conduzirem os negócios e de se relacionarem pode explicar as razões da não-existência das cooperativas na realidade australiana. Assim, a competitividade entre os produtores australianos pode ser analisada de formas diferenciadas. $\mathrm{O}$ aspecto positivo demonstrado está em trazer estímulo para a constante atualização, munindo-os de ferramentas gerenciais para atuar num mercado com competitividade crescente; assim, a responsabilidade pela condução e pelo direcionamento dos negócios, ou seja, pelo sucesso ou fracasso na atividade, é única e exclusivamente deles. Além disso, segundo os produtores, o governo não oferece subsídios e há garantias de auxílio financeiro somente em casos de calamidades. Com base nestes aspectos, infere-se que os produtores australianos, tendo maior autonomia sobre seus negócios, detêm boa capacidade de reagir rapidamente às contingências e de adequaremse às situações de mercado.

Portanto, as indústrias, instituições do governo ou outros tipos de empresas demonstraram exercer pouca contribuição para o estímulo à criação de conhecimento, que se mostra dependente do estímulo que cada um recebe do ambiente, da necessidade de se adequar a ele e do engajamento dos envolvidos na atividade na busca por inovações e melhoramentos contínuos. Os resultados globais são as respostas aos melhoramentos contínuos e, ao mesmo tempo, determinantes da continuidade dos processos evolutivos nas propriedades. Infere-se que os produtores australianos buscam visualizar resultados positivos de suas práticas na atividade para procurar realizar melhoramentos, inovações e garantir mercado para os seus produtos.

Não foi contemplada nesta pesquisa a análise da situação financeira dos produtores pesquisados. Considerando os sinais externos, ou seja, o que ficou visível nas visitas e contatos, os produtores australianos demonstraram dispor de maiores possibilidades de aquisição de recursos tangíveis, tais como maquinário mais moderno, aparato tecnológico para acesso aos recursos da informática, bem como outros equipamentos que facilitam o desenvolvimento das atividades na propriedade, considerando a carência e o alto custo da mão de obra. No que se refere à captação de recursos, afirmaram que as instituições financeiras disponibilizam-lhes financiamento a juros considerados viáveis para a atividade. Pode-se, pois, inferir que eles possuem estrutura econômica para viabilizar o acesso aos recursos de competência, cabendo a cada um direcionar esforços na busca e concretização dos seus objetivos.

A figura 2 representa os fatores que envolvem o processo de criação de conhecimento no elo da produção dos agronegócios brasileiro e australiano, dando ênfase às especificidades das estruturas em cada realidade, demonstrando suas diferentes facetas no que se refere aos fatores envolvidos em cada uma e oferecendo maior dinamismo à análise do processo de criação de conhecimento no elo da produção no agronegócio. 


\section{Conclusões}

O presente trabalho teve como objetivo demonstrar os aspectos presentes na criação de conhecimento em propriedades rurais no Brasil e na Austrália com base no modelo de Nonaka e Takeuchi (1997).

Tanto na realidade brasileira como na australiana, ficou evidente que o aspecto cultural exerce forte influência na ocorrência das trocas e na maior ampliação da atuação das CoPs. Em vista disso, a cultura presente em cada realidade pode influenciar fortemente na forma como as pessoas se relacionam, agem e se comportam, enfim, se elas se propõem ou não a compartilhar o que conhecem e a contribuir para a criação de conhecimento.

A obtenção de informações, originadas de fontes diversas, demonstrou auxiliar significativamente na utilização de ferramentas mais dinâmicas no gerenciamento da propriedade. Contudo, é preciso ter clareza de que o volume de informações não é determinante da criação de conhecimento. A informação necessita ser reconhecida como importante pelo produtor rural para que possa ser transformada em conhecimento. Assim, considera-se que a propriedade, por si só, não cria conhecimentos; ela necessita de pessoas engajadas nas atividades, instigadas a buscar inovações e com um objetivo definido. Por isso, o fato da existência de relacionamentos cria maiores possibilidades de melhorar o aprendizado. Uma organização criadora de conhecimento é vista como um sistema aberto, com permanentes intercâmbios com o ambiente externo, buscando constante adequação, que the garanta sobrevivência e garantia de competitividade no mercado.

No Brasil, a Cotrijal apresentou práticas que estimulam o desenvolvimento da cultura de aprendizagem junto aos associados. No que se refere à Austrália, como os produtores demonstraram não possuir uma estrutura de suporte como a dos brasileiros, eles percebem a necessidade de aprendizagem permanente para se autodesenvolver. Em ambas as realidades, a cultura de aprendizagem é importante porque o nível de informação e conhecimento que o produtor rural possui influencia em suas decisões, trazendo, como resultado, o sucesso ou o fracasso no gerenciamento dos negócios.

Com o reconhecimento da existência das CoPs, podem ser oferecidas maiores possibilidades para discussão, compartilhamento de informações e conhecimentos e, ao mesmo tempo, para otimização da sua utilização. Diante disso, é possível a identificação do local onde estão as melhores práticas e dos especialistas, o que poderá, de alguma forma, através do compartilhamento, oferecer maiores espaços para a otimização dos processos.

Constata-se, portanto, que as CoPs, cuja base da existência se centra na paixão dos produtores por suas atividades, no foco na busca de soluções para problemas comuns, no aprendizado, no desenvolvimento de novas ideias e nos relacionamentos pessoais, podem ser suporte para a criação de conhecimentos. Assim, os grupos que têm oportunidade para realizar discussões podem trazer contribuições para as pessoas conhecerem e assimilarem conhecimentos ao permitirem que todos perguntem e relatem algo novo que tenham tido a chance de conhecer e, ao mesmo tempo, revisem seus pontos de vista.

A observação desses aspectos pode auxiliar na transferência do aprendizado para o conhecimento. O processo de aprendizagem visando à criação de conhecimento pode trazer mais cooperação, engajamento, confiança, criatividade e valorização, pois o conhecimento não pode ser visto separadamente dos aspectos tangíveis e intangíveis da comunidade que cria.

A forma de conduzir os negócios pode afetar a forma como se dá a criação de conhecimento. A propriedade em que as pessoas buscam socializar, questionar e inovar constantemente demonstra haver maior espaço para transformar conhecimento tácito em 
explícito. Pessoas mais abertas ao novo e ao questionamento de suas práticas demonstraram apresentar maiores possibilidades de criar um campo de interação para que o conhecimento seja criado. Assim, a criação de conhecimento está ligada e é dependente de qualidades pessoais, tais como curiosidade, insights, ideias e determinação, ou seja, depende de pessoas aplicando conhecimentos em meios que lhes tragam soluções úteis para velhos e novos problemas.

Um aspecto que esteve presente nas duas realidades foi a falta de hábito de formalidade na maior parte dos procedimentos das propriedades, permitindo inferir que os produtores não querem "gastar tempo" com procedimentos formais ou o que eles denominam de "frescura" (forma de desconsiderar a relevância), dando mais importância às rotinas permeadas pela informalidade nas suas práticas. Porém, parte do que eles consideram desnecessário registrar poderia, talvez, ser utilizada como uma ferramenta importante nas tomadas de decisão na propriedade.

Foi constatado que o conhecimento individual tem suas raízes na prática coletiva. As CoPs combinam capital social, intelectual e estrutural para tornar possível a construção das relações entre as pessoas e o compartilhamento entre elas, cujo resultado é parte das práticas cotidianas dos produtores rurais.

No entanto, as CoPs não se constituem num processo tecnológico, mas num processo social e cognitivo; sua formação não demonstrou ser dependente da tecnologia, mas do estabelecimento de relações informais, por meio das quais os indivíduos utilizam-se de ambientes para definir suas verdades quanto às suas posturas diante dos processos de mudança. As CoPs não parecem surgir e se tornar produtivas rapidamente; necessitam de tempo para se estruturar e produzir resultados, sofrem a influência da cultura e podem ser determinantes do bom desempenho futuro dos empreendimentos, uma vez que são parte natural da vida das organizações.

As pessoas, nas CoPs, necessitam de um ambiente propício para o compartilhamento, no qual não se sintam forçadas a participar. Portanto, confiança é a palavra-chave para haver socialização no contexto da CoP, e o engajamento tem se mostrado importante tanto no nível organizacional como no coletivo e individual.

Este estudo mostrou que há um grande distanciamento entre a existência do conhecimento e a capacidade de torná-lo uma atitude, pois há necessidade de muito mais do que a informação. O ser humano tende, de modo geral, a buscar situações de conforto. $O$ fato de mudar qualquer coisa sempre exige algum esforço, sair da rotina rumo ao desconhecido. Isso se constitui num desafio que muitos evitam, preferindo, então, continuar na situação menos ameaçadora a sua atividade.

O conhecimento tácito dos produtores rurais está presente em diversas formas e meios, podendo tornar-se explícito nos produtos e processos. É importante, quando se pensa em conhecimento tácito, encontrar formas de as pessoas manterem contato frequente, ou seja, criar um campo de interação para que as trocas ocorram e o tácito se manifeste espontaneamente ou ao acaso. As organizações são vistas como um espaço para o convívio humano e para a realização de trocas através da cooperação, do engajamento, da confiança, da criatividade e da valorização. Portanto, é preciso ter em mente que, nesse caso, o mais importante é a aplicação do conhecimento, muito mais que a sua origem.

Assim, acredita-se que um estudo que permita evidenciar contribuições em termos de resultados das CoPs nas realidades, bem como a possibilidade da maior inserção da virtualidade nas práticas de socialização e de qualificação poder dar continuidade a este trabalho. 


\section{Referências}

BATALHA, M. O. Recursos humanos para o agronegócios brasileiro. Brasília: CNPq, 2000.

BHATT, G. D. Knowledge management in organizations: examining the interaction between technologies, techniques, and people. Journal of Knowledge Management, v. 5, n. 1, p. 68-75, 2001.

. Managing knowledge through people. Knowledge and Process Management, v. 5, n. 3, p. 165-171, 1998.

BLACKLER, F. Knowledge, knowledge work and organizations: an overview and interpretation.

Organization Studies, v. 16, n. 6, p. 1021-1046, 1995.

BROWN, J. S.; DUGUID, P. Equilibrismo: como capturar o conhecimento sem matá-lo. In: REVIEW, H. B. Aprendizagem organizacional. Rio de Janeiro: Campus, 2001. p. 48-60.

Organizational learning and

communities-of-practice: toward a unified view of working, learning, and innovation.

Organization Science, v. 2, n. 1, p. 58-81, 1991.

DAVENPORT, T. H.; PRUSAK, L. Conhecimento empresarial: como as organizações gerenciam o seu capital intelectual. Rio de Janeiro: Campus, 1998.

DUGUID, P.; BROWN, J. S. Estrutura e espontaneidade: conhecimento e organização. In: FLEURY, M. T.; OLIVEIRA JR., M. D. M. O. Gestão estratégica do conhecimento: integrando aprendizagem, conhecimento e competências. São Paulo: Atlas, 2001.p. 50-85.

FEIWEL, G. R. The intellectual capital of michal kalecki: a study in economic theory and policy. Knoxville: University of Tennessee Press, 1975.

GHERARDI, S.; NICOLINI, D. The organizational learning of safety in communities of practice. Journal of Management Inquiry. v. 9, n. 1, p. 7-18, 2000.
GOERL, G. F. Knowledge management: cybernetics, professionalization, and knowledge management: an exercise in assumptive theory. Public Administration Review, v. 35, n. 6, p.581-588, 1975.

HEDBERG, B. How organizations learn and unlearn. In: NYSTROM, P. C.; STARBUCK, W. H (Ed.). Handbook of organizational design. New York: Oxford University Press, 1981. p. 3-27.

HEDLUND, G.; NONAKA, I. Models of Knowledge Management in the West and Japan. In: LORANGE, P, et al.. Implementing strategic processes: change, learning and co-operation. Oxford, England: Blackwell Business, p. 117-144, 1993.

HENRY, N. Knowledge management: bureaucracy, technology, and knowledge management. Public Administration Review, v. 35, n. 6, p. 572-578, 1975.

HUBER, G. P. Organizational learning: the contributing processes and the literatures.

Organization Science, v. 2, n. 1, p. 88-115, 1991.

JANK, M. S. O vendaval nas bolsas e o agribusiness. Revista Pecuária de Corte, n. 2, p. 34, 1997.

KRIPPENDORFF, K. Content analysis: an introduction to its methodology. Thousand Oaks, CA: Sage, 2004.

KIMBLE, C.; HILDRETH, P.; WRIGHT, P. Communities of practice: going virtual, University of York, UK, 2001. Disponivel em: <www.users. cs.york.ac.uk/ kimble/research/13kimble.pdf $>$. Acesso em: 15 set. 2002.

LAVE, J. Situating learning in communities of practice. In: RESNICK, L. B.; LEVINE, J. M.; TEASLEY, S. D. Perspectives on socially shared cognition. Washington, D.C: American Psychological Association, 1991. p. 63-82.

LAVE, J.; WENGER, E. Situated learning: legitimate peripheral participation. Cambridge: Cambridge University Press, 1991.

LEONARD, D.; SENSIPER, S. The role of tacit knowledge in group innovation. 
California Management Review, v. 40. n. 3, p. 112-132, 1998.

MCADAM, R.; MCCREEDY, S. A critical review of knowledge management models. The Learning Organization, v. 6, n. 3, p. 91-100, 1999.

MCCAFFERY, J. Knowledge management in fiscal policy formation. Public Administration Review, v. 35, n. 6, p. 598-602, 1975.

MARAKAS, G. M. Decision support systems in the twenty-first century. New Jersey: Publisher Upper; Saddle River: Prentice Hall, 1999.

MURTY, K. S. Building and sustaining communities of practice, asssociation of knowledge Work, 2004. Disponivel em: < http:// www.kwork.org/White\%20Papers/communities. html>. Acesso em: 10 maio 2004.

NONAKA, I A Dynamic Theory of Organizational Knowledge Creation. Organization Science. v. 5, n. 1, 1994, p. 14-37.

. The Knowledge-Creating Company.

Harvard Business Review. v. 69, n. 6, 1991, p. 96-103.

NONAKA, I.; KONNO, N. The concept of "Ba": building a foundation for knowledge creation.

California Management Review, v. 40, n. 3, p. 40-54, 1998.

NONAKA, I.; REINMOELLER, P. Dynamic business systems for knowledge creation and utilization. In: DESPRES, C.; CHAUVEL, D. Knowledge horizons: the present and the promise of knowledge management. Boston: Butterworth-Heinemann, 2000. p. 89-112.

NONAKA, I.; REINMOELLER, P.; SENOO, D. The 'ART' of knowledge: systems to capitalize on market knowledge. European Management Journal, v. 16, n. 6, p. 673-684, 1998.

NONAKA, I.; REINMOLLER, P.; TOYAMA, R. Integrated information technology systems for knowledge creation. In: DIERKES, M. et al. Handbook organizational learning and knowledge. Oxford: Oxford University Press, 2001. p. 827-848.
NONAKA, I.; TAKEUCHI, H. A criação de conhecimento na empresa. Rio de Janeiro: Campus, 1997.

NONAKA, I.; TOYAMA, R.; BYOSIERE, P. A theory of organizational knowledge creation: understanding the dynamic process of creating knowledge. In: DIERKES, M. et al. Handbook organizational learning and knowledge. Oxford: Oxford University Press, 2001. p. 491517.

NONAKA, I.; TOYAMA, R.; KONNO, N. SECI, Ba and Leadership: a unified model of dynamic knowledge creation. Long Range Planning, v. 33, n. 1, p. 5-34, 2000.

NONAKA, I.; UMEMOTO, K.; SENOO, D. From information processing to knowledge creation: a paradigm shift in business management.

Technology in Society, v. 18, n. 2, p. 203-218, 1996.

PEDLER, M. Biography work for organisational learning: strategy or destiny? Management Education and Development, v. 23, n. 3, p. 258-271, 1992.

POLANYI, M. The tacit dimension. New York: Publisher Garden City, 1967.

SACKMANN, S. A. Cultural knowledge in organizations: exploring the collective mind. Newbury Park, Calif: Sage, 1991.

SCHEIN, E. H. Organizational culture and leadership. San Francisco; London: Jossey-Bass, 1985.

Organizational culture. American Psychologist, p. 109-119, Feb. 1990.

SERENKO, A.; BONTIS, N. Meta-review of knowledge management and intellectual capital literature: citation impact and research productively rankings. Management of Innovation and New Technology Research Centre, Canada, 2004. Cdrom.

SPENDER, J. C. Organizational knowledge, learning and memory: three concepts in search of a theory. Journal of Organizational Change Management, v. 9, n. 1, p. 63-78, 1996. 
. Pluralist epistemology and the

knowledge-based theory of the firm.

Organization, v. 5, n. 2, p. 233-256, 1998.

STEWART, T. A. Capital intelectual: a nova vantagem competitiva das empresas. Rio de Janeiro:Campus, 1998.

SONKA, S. T. et al. Production agriculture as a knowledge creating system. The International Food and Agribusiness Management Review, v. 2, n. 2, p. 165-178, 1999.

VANCLAY, F. The social context of farmers' adoption of environmentally sound farming practices. In: LAWRENCE, G.; VANCLAY, F.; FURZE, B. Agriculture, environment and society: contemporary issues for Australia. South Melbourne, Vic: Macmillan, 1992. p. 123-127.

. Communities of practice: learning, meaning, and identity. Cambridge, UK: Cambridge University Press, 1998.

. Communities of practice: the social fabric of a learning organization. The Healthcare Forum Journal, v. 39, n. 4, p. 20-25, 1996.

. Communities of practice: the structure of knowledge stewarding. In: DESPRES, C.; CHAUVEL, D. Knowledge horizons: the present and the promise of knowledge management. Boston: Butterworth-Heinemann, 2000. p. 205265.

WENGER, E. C.; SNYDER, W. M. Communities of practice: the organizational frontier. Harvard Business Review, v. 78, n. 1, p. 139-145, 2000. . Comunidades de prática a fronteira organizacional. In: REVIEW., H. B. Aprendizagem organizacional. Rio de Janeiro: Campus, 2001. p. 9-26.

WENGER, E; MCDERMOTT, R.; SNYDER, W. Cultivating communities of practice: a guide to managing knowledge. Boston: Harvard Business School Press, 2002. 